\title{
Los Bienes Patrimonio de la Humanidad en Andalucía
}

Juan Manuel Becerra García

Arquitecto

Jefe del Servicio de Protección del Patrimonio Histórico de la Dirección General de Bienes Culturales

\section{Resumen}

La Tramitación de un expediente de Patrimonio Mundial difiere de forma notable de la de un bien del patrimonio histórico andaluz. La justificación de sus valores se apoya en su "valor universal excepcional" ya que la Lista del Patrimonio Mundial no pretende ser una lista exhaustiva sino representativa de

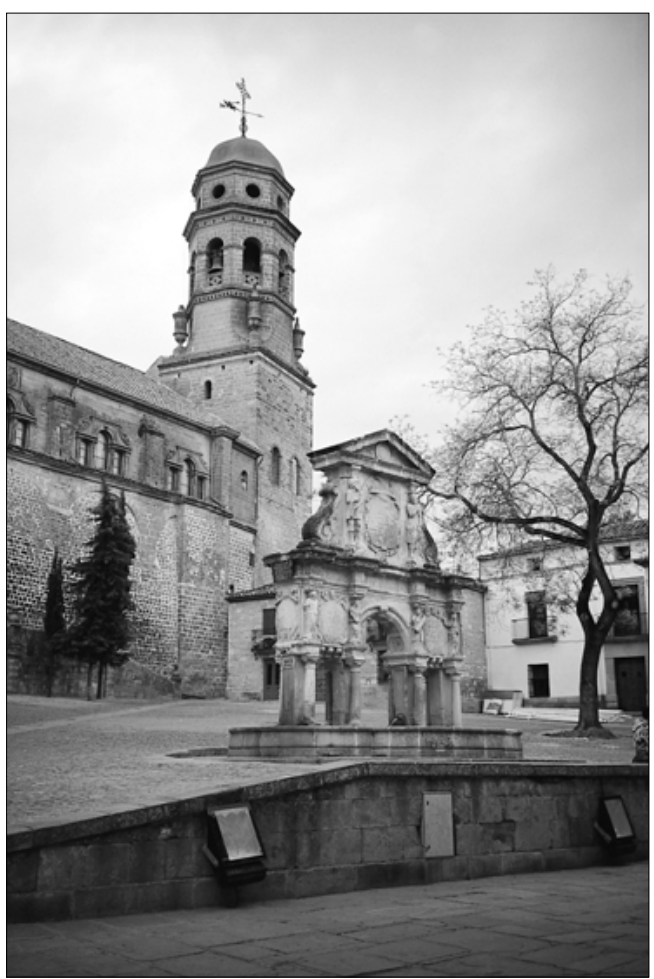

los valores culturales y naturales de la humanidad. Además los bienes en ella inscritos, deben er un referente claro de cómo intervenir o conservar el patrimonio cultural. Por ello los bienes que se desee inscribir deben responder a los criterios de autenticidad e integridad y tener planes de protección y gestión adecuados.

En Andalucía son varios los bienes declarados como Patrimonio Mundial y numerosos los inscritos en la Lista indicativa previa a la formulación de las candidaturas. En estos momentos las ciudades de Úbeda y Baeza se encuentran en la recta final del proceso como candidatas para ser incluidas en la Lista del Patrimonio Mundial.

Para la "Lista de Obras Maestras del Patrimonio Oral e Inmaterial" Andalucía propone incluir el flamenco.

\section{Palabras clave}

Patrimonio mundial / Bienes incritos / Candidaturas / Autenticidad / Conservación / Úbeda / Baeza.

Hace apenas unas semanas tuve la oportunidad de acompañar al evaluador designado por Icomos para informar sobre la candidatura de las ciudades de Úbeda y Baeza para Patrimonio de la Humanidad. Con la visita del evaluador se inició la recta final para la "declaratoria" de las dos ciudades, siendo determinantes sus conclusiones para el buen fin de la candidatura!.

Las ciudades de Úbeda y Baeza pretenden, de esta manera, sumarse a la corta pero selecta lista de bienes de Andalucía, que han sido incluidos por la Unesco en la Lista del Patrimonio Mundial2. En 1984 fueron declaradas Patrimonio Mundial Cultural la Mezquita de Córdoba y la Alhambra y Generalife de Granada, que diez años después se amplían al declararse el sector próximo del Centro Histórico de 
Para que un bien pueda ser presentado como candidato a Patrimonio Mundial, antes debe figurar en la llamada Lista Indicativa del Patrimonio Mundial. Lista que la Unesco ha cerrado al menos para los diez próximos años. Andalucía es una de las Comunidades que más bienes ha inscrito en la Lista Indicativa.

Córdoba y el Barrio del Albaicín de Granada. En 1987, se declara la Catedral, Alcázar y Archivo de Indias de Sevilla, y el Arte Levantino en 1997. Como Patrimonio Mundial Natural se encuentra declarado el Parque Nacional de Doñana desde 19943.

Pero, ¿cuáles son las principales características que debe poseer un bien para ser declarado Patrimonio de la Humanidad, y qué efectos posee?

Las expectativas que despierta la declaración de un bien como Patrimonio Mundial y el somero conocimiento que suele tenerse sobre la tramitación de este tipo de expedientes, hace que continuamente se solicite a la Consejería de Cultura la declaración de tal o cual bien, que, a juicio del solicitante, tiene "evidentes" valores universales, desde la perspectiva de los parámetros establecidos en las legislaciones autonómica o estatal para los bienes del patrimonio histórico.

No sólo la tramitación de un expediente de Patrimonio Mundial difiere de forma notable de la de un bien del patrimonio histórico andaluz, si no que la justificación de sus valores y las consecuencias de la declaración responden al reconocimiento internacional que alcanzan.

La diferencia fundamental entre el Patrimonio Mundial y el patrimonio histórico de una nación radica en el concepto de "valor universal excepcional" recogido en la Convención para la Protección del Patrimonio Mundial Cultural y Natural, y desarrollado en las Orientaciones para la aplicación de la Convención que se revisan periódicamente en el seno del Comité del Patrimonio Mundial.

No basta, simplemente, con ser un elemento patrimonial de primer orden para nuestra Comunidad o Estado, sino que éste además debe tener relevancia reconocida por la comunidad cultural internacional. El propio Comité ha precisado con detalle los criterios que se deben aplicar para establecer la Lista. Un bien cultural tiene, por ejemplo, que haber ejercido una gran influencia, o aportar un testimonio único, o
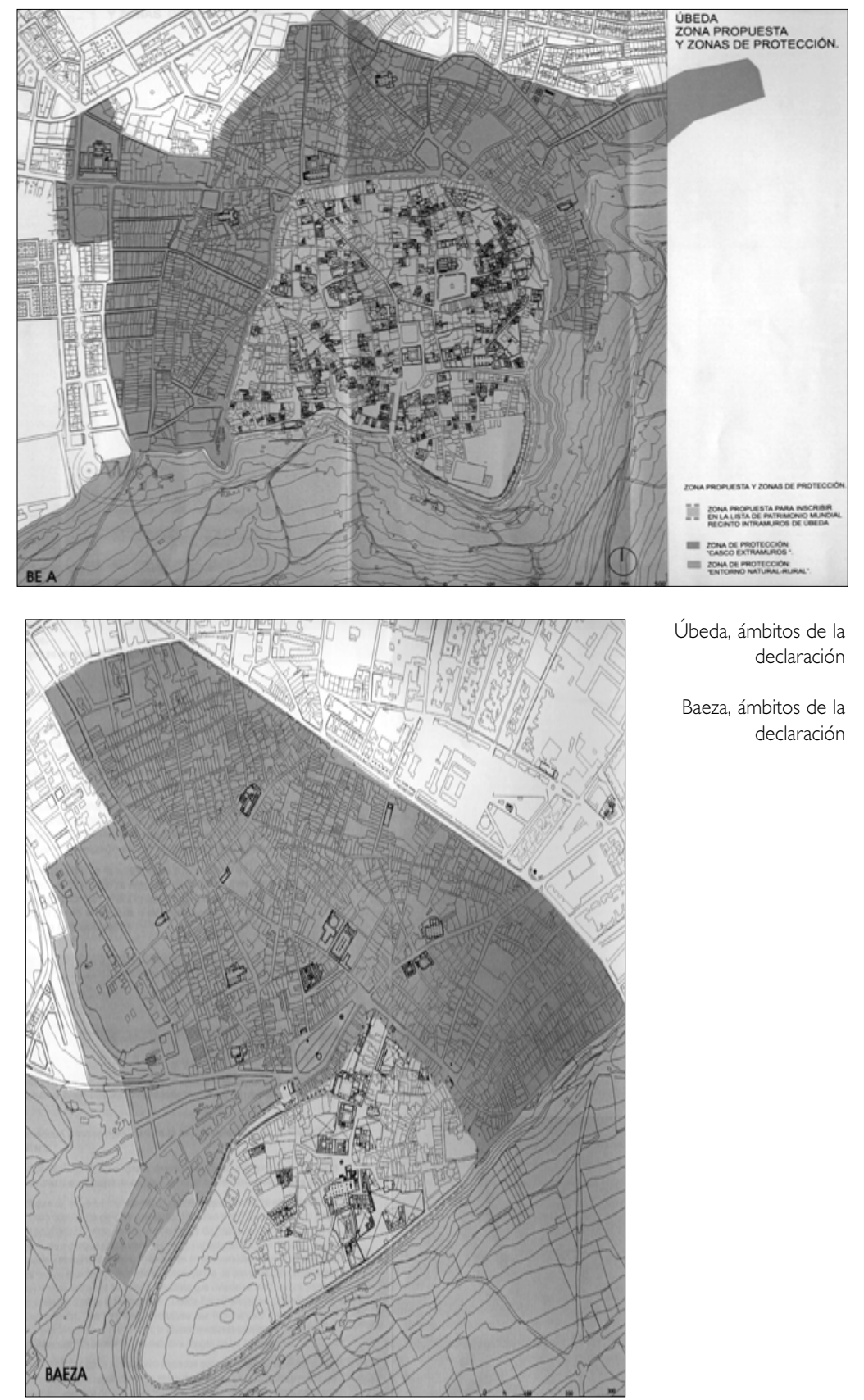

Úbeda, ámbitos de la declaración

Baeza, ámbitos de la declaración 

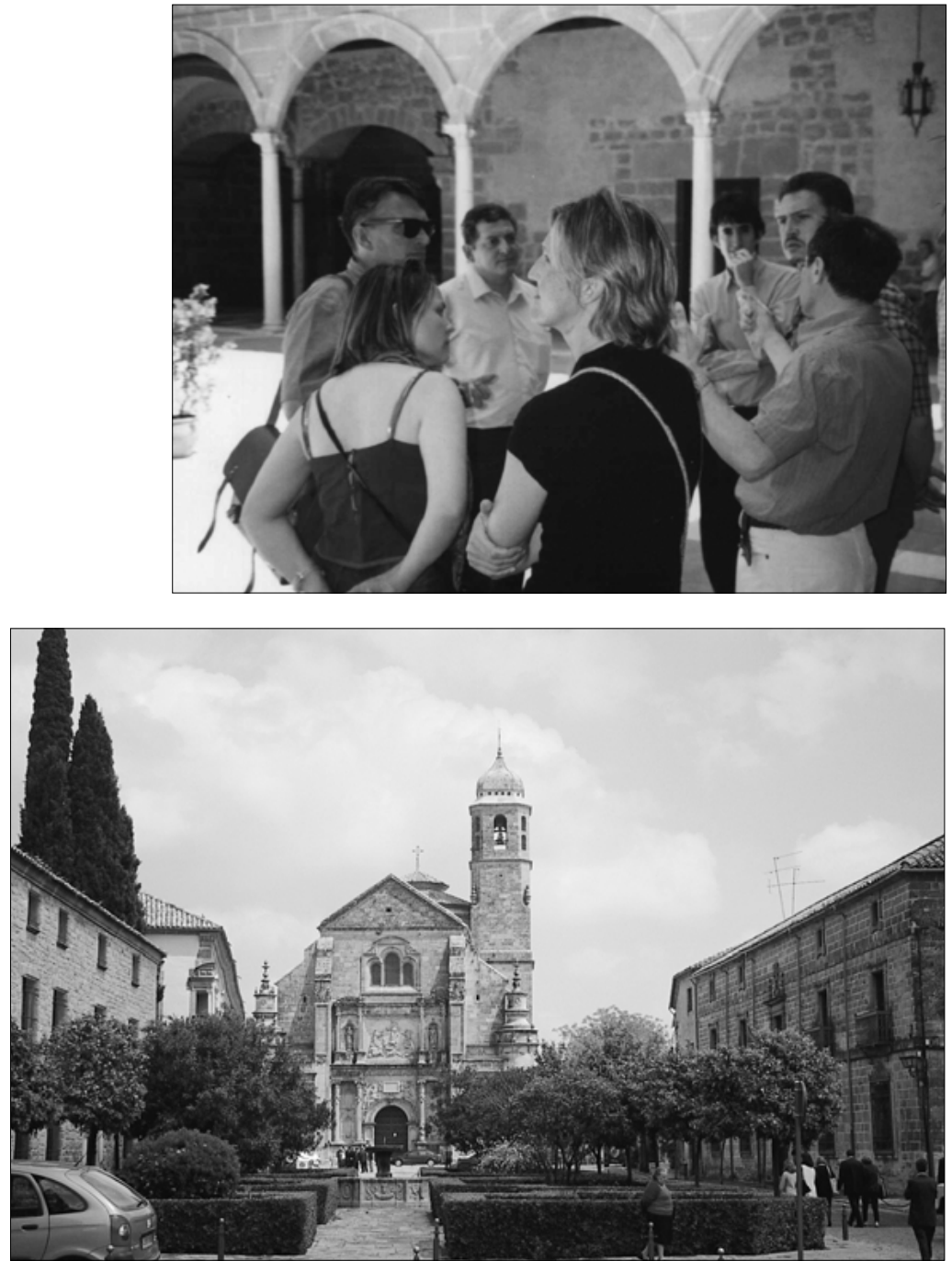

Visita del evaluador al Hospital de Santiago junto Marcelino Sánchez, alcalde de Úbeda, Rufina Fernández, redactora y coordinadora del expediente y Diego Fernández, representante de Ministerio de Cultura, atendiendo las explicaciones de Pedro Galera, catedrático de Historia y colaborador en e expediente

Plaza Vázquez de Molina de Úbeda

Fotos: J. Manuel Becerra G estar asociado a ideas o creencias universales, o constituir todavía un eminente ejemplo de hábitat humano tradicional representativo de una cultura ${ }^{4}$.

Así, la reciente candidatura del Yacimiento de Atapuercas, se valoró positivamente, entre otros aspectos, al constituir un testimonio único y excepcional de un momento del desarrollo y expansión de la especie humana. En cambio, uno de los aspectos más significativos de la candidatura de la Universidad de Alcalá de Henares fue el hecho de que fuera tomada como modelo para la constitución de la mayoría de las Universidades de la América de habla hispana que adoptaron sus estatutos, organización e incluso, en alguna ocasión, su arquitectura.

En el caso de los actuales bienes del Patrimonio Mundial en Andalucía éstos fueron declarados en cuanto constituyen testimonios excepcionales de culturas de proyección universal y fueron a su vez modelo de referencia obligado para múltiples bienes culturales no sólo dentro de nuestras fronteras.

En el caso de la candidatura de Úbeda y Baeza 5 , la documentación que formaliza el expediente recoge que "...la excepcionalidad de las dos ciudades estri- ba en que se desarrollan y estructuran a lo largo de la historia de forma dual. Una dualidad complementaria que las hace funcionar en muchos aspectos como una sola ciudad, con afinidades y rasgos propios y matices diferenciales que caracterizan su morfología y devenir histórico hasta el presente". También destaca el florecimiento de un "...Renacimiento muy personalizado en el que el desarrollo de innovaciones constructivas en el campo de la Estereotomía permitió adoptar soluciones arquitectónicas complejas, que han tenido una constatada y relevante repercusión en la arquitectura de la América Española". Además, Úbeda y Baeza "...como lugar de confluencias, posibilitó la generación de un espacio de interacciones culturales, donde llegan a fundirse las concepciones humanistas con el substrato islámico en el urbanismo y la arquitectura, y con el substrato judío en la potenciación del humanismo a través de su Universidad6".

Es importante que las candidaturas evidencien, claramente, los valores que sustentan su excepcionalidad y razonen, adecuadamente, los rasgos que las diferencian de otros bienes ya declarados. La Lista del Patrimonio Mundial no pretende ser una lista exhaustiva sino representativa de los valores culturales y naturales de la humanidad.

Otro de los efectos de la Lista es que, los bienes en ella inscritos, deben ser un referente claro de cómo intervenir o conservar el patrimonio cultural. Por ello, además de alguno de los criterios antes reseñados, cualquier bien que se pretenda inscribir debe reunir dos condiciones previas: responder en su concepción, materiales y ejecución al valor de autenticidad e integridad, y gozar de protección jurídica y mecanismos de gestión adecuados que aseguren su conservación.

El valor de "autenticidad" viene definido en el Documento de Nara (Japón) de noviembre de 1994, y pretende reconocer el grado de pervivencia de los materiales y métodos de construcción tradicionales en el ámbito de la declaratoria. En el punto 10 del Documento se dice "La autenticidad se muestra como el factor cualitativo esencial en cuanto a la credibilidad...".

Para ser valorada una candidatura no basta sólo con poseer valores universales excepcionales, sino que son determinantes las condiciones en las que nos ha llegado el bien.

Este requisito sigue de alguna forma la tradición de algunos países como EEUU o Méjico en donde sólo se considera bien patrimonial, y se protege por sus legislaciones, aquellos bienes que poseen un buen estado de conservación. En la legislación del patrimonio histórico de Andalucía, el buen estado de conservación de un bien no es requisito indispensable para su valoración cultural y protección jurídica.

Los conceptos de autenticidad e integridad para el ámbito de la declaratoria se han destacado en el ca- 
so de la propuesta de declaración de Úbeda y Baeza, a los que se suma el continuado esfuerzo inversor de las administraciones públicas para el mantenimiento y conservación de sus valores 7 . Es esto último, una de las grandes basas de la candidatura. No es habitual un compromiso tan firme desde los poderes públicos en la protección y conservación del patrimonio cultural. De hecho, ambos municipios cuentan con declaraciones como conjunto histórico desde mediados del siglo $X X$, en fechas cercanas a las declaraciones de las ciudades de Cáceres - Salamanca, y cuando entra en vigor la Ley del Patrimonio Histórico Español de 1985, no tardan en dotarse de Planes Especiales de Protección para el Conjunto Histórico, siendo pioneras en Andalucía en esta materia.

Así mismo, en estos municipios se encuentran algunas de las actuaciones en materia de rehabilitación de iniciativa pública más premiadas por sus ejemplares intervenciones en recuperación del patrimonio histórico, como es el caso de la rehabilitación del antiguo Convento de Santa Catalina para viviendas sociales, o la recuperación del Convento de San Francisco en Auditorio, ambos edificios en Baeza.

Conscientes los municipios de la necesidad de aunar y coordinar sus actuaciones en beneficio de la salvaguarda y promoción de su patrimonio, en 1998 tuvo lugar el Hermanamiento de las dos ciudades, y poco después, se creó el Consejo Asesor del Patrimonio de Úbeda y Baeza, que ya ha impulsado algunas actuaciones de forma unitaria como es el caso de la señalización normalizada de los monumentos, edificaciones y espacios singulares de ambas ciudades.

La conservación de los bienes incluidos en la Lista del Patrimonio Mundial es una prioridad del Comité del Patrimonio Mundial. De hecho, si un país incumple sus obligaciones derivadas de la Convención corre el riesgo de que sus bienes sean retirados de la Lista. El bien se incluye en la llamada Lista del Patrimonio Mundial en Peligro, si se justifica la alerta, hasta que la agresión desaparezca o resulte expulsado de la Lista. Hasta la fecha ningún bien Andaluz ha sido incluido en la Lista del Patrimonio Mundial en Peligro.

Desde hace unos años se están promoviendo campañas sistemáticas para verificar el estado de conservación en que se encuentran los bienes de la Lista del Patrimonio Mundial. Estas campañas se desarrollan por continentes, estando previsto el informe de los bienes de la Comunidad Andaluza para este año.

Conviene también recordar que la excesiva representación de bienes en el ámbito europeo, en especial los de España e Italia, ha hecho que la Unesco quiera dar prioridad a la inclusión de bienes de países y latitudes poco representados. Esto significa que a partir de ahora las declaraciones de bienes españoles se van a otorgar con cuenta gotas entre los bienes aprobados en la Lista Indicativa.

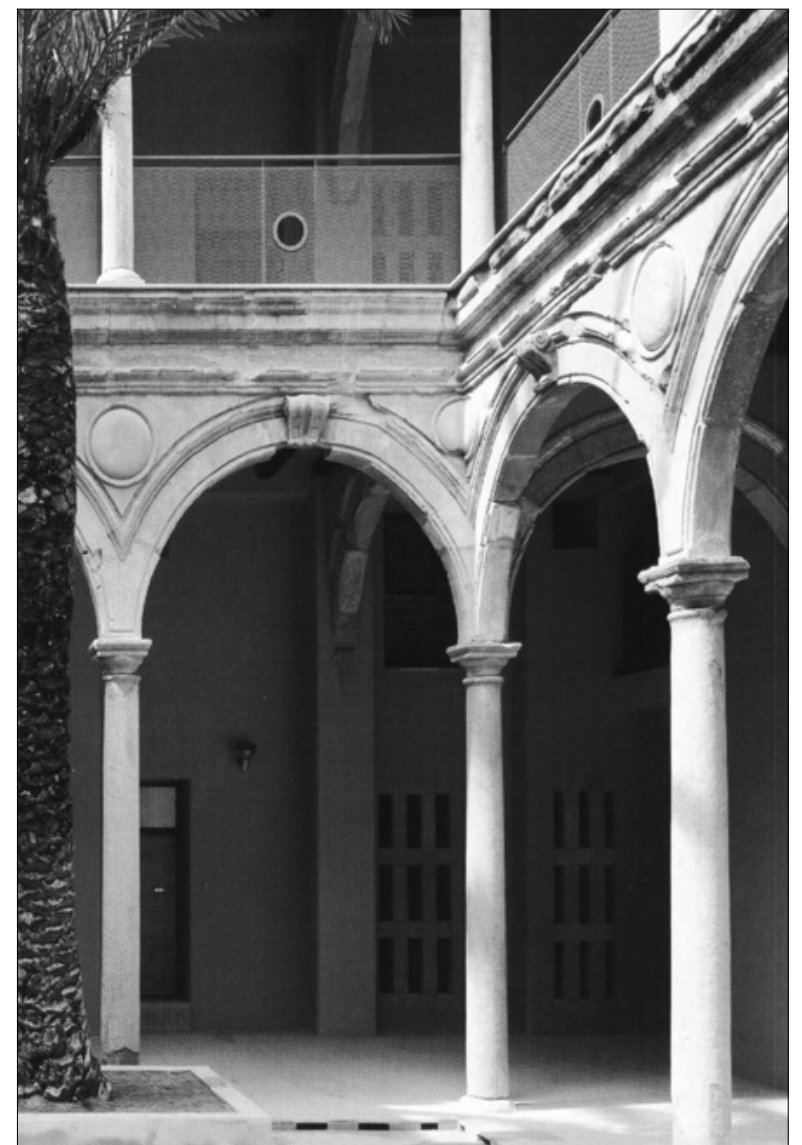

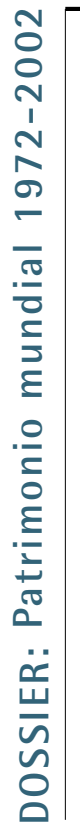

Para que un bien pueda ser presentado como candidato a Patrimonio Mundial, antes debe figurar en la llamada Lista Indicativa del Patrimonio Mundial. Lista que la Unesco ha cerrado al menos para los diez próximos años. Andalucía es una de las Comunidades que más bienes ha inscrito en la Lista Indicativa.

Pero hay algo que la Unesco tenía en el olvido: el patrimonio inmaterial. Desde la creación de la Lista del Patrimonio Mundial por la Convención del Patrimonio Mundial de 1972, ésta se había centrado exclusivamente en proteger el patrimonio material, lo que relegó un gran número de elementos culturales pertenecientes a menudo a las culturas del sur que se fundamentan en la diversidad cultural. A tal efecto la Unesco crea la Lista de Obras Maestras del Patrimonio Oral e Inmaterial, que posee una reglamentación propia y cuyas primeras declaraciones se produjeron el 18 de mayo de 2001 . En la línea crea$\mathrm{da}$, el patrimonio oral e inmaterial adquiere una importancia capital en tanto que factor vital para la identidad cultural, la promoción de la creatividad y la preservación de la diversidad cultural.

La propuesta de Andalucía para ser inscrita en la Lista de Obras Maestras del Patrimonio Oral e Inmaterial es el Flamenco. Dicha propuesta cuenta con gran respaldo social y ha sido objeto de numerosas solicitudes, entre las que se incluye una iniciativa parlamentaria. Además, sus valores como fenómeno que ha alcanzado cualquier lugar del mundo, le confieren un fuerte acento de universalidad que puede contribuir al buen fin de la candidatura.
Rehabilitación del antiguo Convento de Santa Catalina en Baeza para viviendas sociales. Actuación de la COPT de 1997 Foto: Martín García 
I. La candidatura de Úbeda y Baeza para Patrimonio Mundial fue presentada inicialmente en 1989, siendo rechazada por insuficiencia en la justificación. Tras exhaustivos estudios complementarios se vuelve a presentar en el año 2000, pero se acuerda con el Ministerio de Cultura su paralización ante el gran número de candidaturas que el estado Español acumula ese año. En la actualidad es la única candidatura presentada por el Gobierno Español.

2. La Convención para la Protección del Patrimonio Mundial Cultural y Natural, aprobada el 16 de noviembre de 1972 durante la celebración de la $17^{a}$ reunión de la Conferencia General de la Organización de las Naciones Unidas de la Educación, define el concepto de Patrimonio Mundial desde la perspectiva cultural y natural, y crea para su reconocimiento la Lista del Patrimonio Mundial.

3. Hasta la fecha Andalucía no posee declarado ningún bien de carácter mixto Patrimonio Cultural-Natural, aunque sí se contemplan en la Lista Indicativa.

4. Los criterios establecidos por el Comité del Patrimonio Mundial para valorar las candidaturas a Patrimonio Mundial son:

I.- Constituir una obra maestra del genio creador del hombre.

2.- Haber ejercido una influencia considerable, en un período dado, o en un área cultural determinada, sobre el desarrollo de la arquitectura, las artes monumentales, el planeamiento urbano o la creación de paisajes.

3.- Aportar un testimonio único, o al menos excepcional, de una civilización o de una tradición cultural desaparecida.

4.- Ofrecer un ejemplo eminente de un tipo de construcción o de conjunto arquitectónico o de paisaje que ilustre un período significativo de la historia humana.

5.- Constituir un ejemplo sobresaliente de establecimiento humano o de ocupación del territorio representativos de culturas tradicionales, sobre todo cuando son vulnerables a mutaciones irreversibles.
6.- Aparecer directa o materialmente asociado a acontecimientos o tradiciones vivas, ideas, creencias u obras artísticas y literarias que tengan una significación universal excepcional. El Comité considera que este criterio en solitario no debería justificar una inscripción en la Lista, salvo en circunstancias excepcionales o cuando concurra con otros criterios.

5. Hay que recordar que, a diferencia de lo que ocurre en nuestra legislación sobre el patrimonio histórico, es el estado parte que presenta su candidatura el que tiene que justificar y acreditar los valores universales de la propuesta, no estando previsto que las candidaturas se realicen de oficio por parte de la Unesco. No obstante, se suele contar con la ayuda de los expertos de lcomos que asesoran sobre los aspectos técnicos de los expedientes.

6. Los estudios técnicos que apoyan la justificación de la candidatura se pueden consultar en la dirección www.juntaandalucia.es/cultura.

7. Al contrario de lo que se piensa habitualmente el hecho de que un bien sea declarado Patrimonio Mundial no supone que la Unesco esté comprometida a la realización de inversiones para su conservación, todo lo contrario su papel será el de exigir al estado parte que promovió la declaración que adopte las medidas necesarias para la conservación del bien y su entorno.

8. Si la administración andaluza no hubiera actuado con urgencia y eficacia en el Parque Nacional de Doñana, posiblemente este bien se hubiera incluido en la Lista del Patrimonio Mundial en Peligro. 